Cahiers $d u$ MONDE RUSSE

\section{Cahiers du monde russe}

Russie - Empire russe - Union soviétique et États indépendants

$53 / 4 \mid 2012$

Varia

\title{
Boris Pilniak, Racines du soleil japonais
}

\section{Léon-Paul Schaub}

\section{OpenEdition \\ Journals}

Édition électronique

URL : http://journals.openedition.org/monderusse/7892

DOI : 10.4000/monderusse.7892

ISSN : 1777-5388

Éditeur

Éditions de l'EHESS

Édition imprimée

Date de publication : 15 décembre 2012

ISSN : 1252-6576

\section{Référence électronique}

Léon-Paul Schaub, «Boris Pilniak, Racines du soleil japonais », Cahiers du monde russe [En ligne], 53/4 I 2012, mis en ligne le 02 décembre 2013, Consulté le 24 septembre 2020. URL : http://

journals.openedition.org/monderusse/7892 ; DOI : https://doi.org/10.4000/monderusse.7892

Ce document a été généré automatiquement le 24 septembre 2020

(c) École des hautes études en sciences sociales 


\title{
Boris Pilniak, Racines du soleil japonais
}

\author{
Léon-Paul Schaub
}

\section{RÉFÉRENCE}

Boris PILNIAK, Racines du soleil japonais, suivi de Boris Pilniak au Japon en 1926

[Préfacé, annoté et commenté par Dany Savelli, traduit par Barbara Eydely]. Paris :

Éditions du Sandre, 2010, 269 p.

1 L'œuvre de Boris Pilniak (1894-1938) est connue pour ses audaces formelles propres, tout comme pour le témoignage qu'elle porte sur les relations entre la création artistique, le fait révolutionnaire et la formation du régime de l'Union soviétique, jusqu'à l'exécution de l'écrivain dans le contexte de la Grande Terreur stalinienne. Le volume que présente Dany Savelli porte sur un texte édité du vivant de Pilniak à partir des chroniques publiées et des notes qu'il avait prises au cours de son voyage au Japon au printemps de 1926. Le travail d'enquête de Dany Savelli aux sources de la presse japonaise et des archives de la police politique de l'Empire nippon reconstruit pour le lecteur les contextes matériels, politiques, policiers et culturels indispensables pour comprendre la genèse, la forme et la réception de ce livre. Pour parvenir à ce tour de force il fallait déployer une connaissance profonde et érudite de la façon dont la société et la littérature russes et soviétiques ont imaginé leurs relations avec l'Extrême-Orient. C'est ainsi que l'enquête adopte quatre directions. D'abord, examiner le rôle que les autorités soviétiques pouvaient attribuer à des intellectuels comme Boris Pilniak comme rouages ou instruments des relations internationales. Puis décrire les ressources idéologiques et culturelles que ce type d'artiste pouvait mobiliser pour affronter l'altérité extrême-orientale. Ensuite, reconstituer le jeu politique et policier japonais tout au long de la visite d'un écrivain, tenu par les uns comme un témoin de la réalité soviétique, pour les autres comme un propagandiste si ce n'est comme un espion. Enfin, analyser les réceptions japonaise et soviétique des articles publiés dans la presse japonaise et du petit volume Racines du soleil japonais en URSS, y compris les 
réécritures auxquels Pilniak a lui-même soumis son livre, dans les différentes rééditions postérieures, pour enregistrer les effets de son second voyage au Japon en 1932 et surtout pour répondre aux exigences du régime à l'égard des écrivains. Le travail est conduit sur ces trois fronts à la fois dans l'étude qui suit la traduction du texte de Pilniak et dans le dense appareil de notes qui en éclaire toutes les difficultés.

2 Jamais Boris Pilniak n'a joui d'un statut comparable à celui d'autres écrivains engagés aux côtés de la révolution d'Octobre comme Vladimir Majakovskij. Il fait toutefois partie des créateurs russes qui avaient été autorisés à voyager dans plusieurs pays européens dans les années 1920 : Allemagne, Grande-Bretagne, Norvège, Grèce. Son inventivité stylistique le plaçait à grande distance d'une littérature didactique, réaliste ou animée par la présence de "héros positifs ». Sa méthode de travail et sa recherche esthétique font grand usage de la technique du collage, qui n'est pas sans rappeler les propositions des cubistes d'avant la Grande Guerre. Il s'agit d'assembler dans une même prose des fragments de textes issus de genres et même de supports les plus variés. De ce point de vue, le volume publié en 1926, à son retour du Japon, demeure fidèle à cette méthode, puisqu'il est composé de la version russe de certains des articles livrés aux journaux japonais, de notes de son journal personnel, et d'extraits de divers types. Le plaisir du collage provient en partie du caractère réellement disparate des pièces convoquées, mais peut-être surtout d'une écriture de la discontinuité qui fabrique le caractère hétéroclite des éléments autant qu'elle l'enregistre.

3 Le voyage de Pilniak fut organisé à l'initiative du grand quotidien Asahi Shinbun. La signature de la convention de Pékin en 1925 et une politique diplomatique des petits pays, marquée par un pragmatisme affirmé, avaient permis de mettre en place des échanges soviéto-japonais, dans un contexte de méfiance réciproque. L'écrivain soviétique arrivait dans un pays dans lequel la littérature russe traduite exerçait une influence considérable que la guerre de 1904-1905 n'avait en rien démenti: Tolstoj demeurait l'écrivain occidental le plus lu dans l'archipel, et le prestige de son œuvre emmenait avec lui Čehov, Dostoevskij, Gor'kij et Turgenev.

4 Le harcèlement par la police locale dont il est victime tout au long de son séjour constitue un des thèmes du livre. La surveillance est organisée par les autorités japonaises bien avant le débarquement de Pilniak dans l'archipel. En effet, son voyage le conduit à Harbin quelque mois après que l'Union soviétique a repris pied en Mandchourie réduisant d'autant la sphère d'influence japonaise en Chine du Nord. Telle qu'il la décrit, cette surveillance policière peut se donner à lire comme une allusion voilée aux méthodes tchékistes en usage dans son propre pays. Il explique, en effet, qu'au Japon l'art de s'insinuer dans la vie d'autrui pour mieux en deviner les desseins et prévenir la mise en œuvre de ceux-ci est très honorable - alors que l'exercice pourrait sembler vil aux Européens. C'est pourquoi, observe Pilniak, on peut à juste titre considérer que tout sujet japonais en voyage à l'étranger est un espion en puissance au profit de son pays. Or c'est précisément ce dont Pilniak lui-même est soupçonné par les autorités nippones.

$5 \quad$ Les Racines du Soleil japonais se divise en trois parties. Un prologue évoque les étapes $d u$ voyage qui le conduisent de Russie au Japon. Il est suivi par une série de chroniques sur diverses dimensions de la vie japonaise au regard de la brève expérience que Pilniak put en avoir. Dans l'épilogue, l'écrivain esquisse une réflexion sur la façon dont sa conception du monde a pu se trouver bouleversée par le spectacle des réalités japonaises. Car c'est essentiellement un impact visuel dont Pilniak rend compte dans la 
mesure où, en dehors des épisodes au cours desquels il fut amené à s'adresser à des intellectuels et journalistes japonais, sous forme de conférences ou de causeries, avec le concours d'interprètes, le reste de son expérience de l'archipel est limité par sa méconnaissance totale de la langue.

6 Un des thèmes qui retient son attention dans plusieurs des articles qu'il a rédigés autant que la censure le lui a permis, demeure sa rencontre avec l'art d'Orient. Ce qui, au premier abord, pourrait apparaître comme un cliché, «l'art européen repose sur le temps et vieillit avec l'histoire du temps malgré son effort constant de marcher avec les époques, tandis que l'art de l'Orient, fondé sur les conventions du beau, des hauts sentiments et de la beauté, a rejeté le temps s'est placé au-dessus de lui », vaut pour la conclusion qu'il en tire: «Au Japon, j'ai perdu mon point de vue sur l'art de la littérature ». En effet, le rapport à la temporalité qu'il croit parvenir à décoder le renvoie à la posture qui demeure la sienne dans son contexte russe, celui de l'appartenance à une avant-garde dans l'ordre de la création artistique. Se trouve ainsi convoqué le dilemme de l'artiste happé par le désir d'accoucher d'un monde nouveau mais refusant de dresser un rempart contre le passé artistique et littéraire. Le détour par le Japon, de façon dialectique, permet à Pilniak de donner à contempler un tout autre rapport au temps historique.

7 Dans le même ordre d'idée, l'observateur russe perçoit que les grands accidents naturels, éruptions volcaniques et tremblements de terre, offrent le spectacle d'un temps géologique où les événements se succèdent à un rythme et une fréquence qui intervient dans la vie quotidienne des sujets. Alors que le temps des croyances, des arts, de la définition des goûts et des mœurs, est installé dans une lenteur, parfois une immobilité, qui semble se poser hors de l'histoire de la société. Ce qui dans cette inversion des temporalités reste en jeu est un rapport des hommes à la nature, dans une culture singulière, au regard de l'ambition progressiste et humaniste de transformation de cette nature par les hommes. Nul doute que la soumission japonaise aux lois naturelles relève d'un choix de société et ne doit rien à une sorte primitivisme spontané : « Les Japonais meurent en ordre, quand il y a un tremblement de terre, ils s'arrêtent de bouger et attendent patiemment la mort ».

8 La fascination visuelle passe par les paysages japonais, la calligraphie, le maquillage de geishas. Les descriptions du Mont Fuji adoptent les catégories japonaises, car elles reposent sur l'anthropomorphisme (le Fujisan) et la divinisation de cette montagne qui demeure pour le peuple japonais un dieu protecteur. Hors des échanges verbaux et audelà des impressions visuelles, Pilniak s'attache à d'autres sensations, par exemple sonores. C'est le cas dans le beau passage où il décrit le bruit des geta (sabots en forme de sandales) : «Au Japon, il y a trois bruits. Le silence, le mutisme des parcs, le bruit d'une cascade qui tombe, d'un ruisselet qui murmure dans la campagne, et le bruit humain des getas".

9 L'invitation de Boris Pilniak au voyage mental au Japon, ou à travers le Japon, ne peut faire l'objet d'une proposition synthétique. L'admiration que son ouvrage a suscitée en son temps tient sans doute au fait que la technique du collage, par inversion poétique, convertit les stéréotypes en leur contraire. Le matériau brut, fait de clichés et d'impressions pour l'essentiel non fondées sur la parole, dans la composition que Pilniak en donne, se trouve chargé d'une puissance d'évocation et d'une capacité de transmission de l'émotion extraordinaires. Les discontinuités narratives tout comme le refus du lissage qu'aurait exigé un exposé conventionnel ne peuvent que séduire, 
aujourd'hui, tous ceux qui attribuent à la littérature la faculté de produire des connaissances. Mettant en valeur toute la richesse de ce texte volontairement énigmatique, le gros travail d'édition et de mise en contexte entrepris par Dany Savelli permet au lecteur de prendre toute la mesure de l'importance du livre de Pilniak. 